\title{
Experimental Measurements of the Thermal Conductivity of Insulant Elements Made of Natural Materials: Preliminary Results
}

\author{
F. Baccilieri ${ }^{1}$, R. Bornino ${ }^{1}$, A. Fotia ${ }^{1}$, C. Marino ${ }^{2}$, A. Nucara ${ }^{2}$ and M. Pietrafesa ${ }^{2 *}$ \\ ${ }^{1}$ DICEAM Department - Mediterranea University of Reggio Calabria \\ ${ }^{2}$ DIIES Department - Mediterranea University of Reggio Calabria
}

Email: matilde.pietrafesa@unirc.it

\begin{abstract}
Current policies addressing the energy efficiency of building constructions urge planners and manufacturers to properly design the edifice envelope which has to be conceived with a view to both optimizing its thermal performances and complying with the local and national regulations. To achieve this target, for the last few years, researchers involved in building industry have been devising new structures able to realize proper levels of envelope thermal insulation, also employing materials characterized by low environmental impacts owing to their natural origin (such as vegetal fibers) or because derived from industrial/ agricultural process waste. As a contribution to this topic, the purpose of this paper is to assess the insulation features of various structures made up of totally natural and biocompatible materials, in order to try to single out the optimal configurations. The studied mixtures, as a matter of fact, consist of a natural binder (such as hydraulic lime NHL 3.5) and a biocompatible inert material (such as dry platanus acerifolia fruit, natural cork, etc.) with various mass ratio compositions.

The measured parameter is the thermal conductivity and the method used is the one stated by the ASTM C518 - 04 Standard, which employs a heat flow meter apparatus establishing steady state one-dimensional heat flux through a test specimen between two parallel plates at constant but different temperatures. Fourier's law of heat conduction is, hence, used to calculate thermal conductivity of the specimen.
\end{abstract}

Keywords: Natural and recycling materials, Thermal conductivity, Building insulation.

\section{INTRODUCTION}

It is conventional wisdom that the main part of the European policies addressing the reduction of $\mathrm{GHG}$ emissions and energy use, with a view to contributing to the energy independence of the EU, specifically regards the building and transport sector [1]-[4].

As concerns the former, ambitious requirements for energy performance in buildings are established.

As a matter of fact, buildings are responsible for $40 \%$ of energy consumption and $36 \%$ of $\mathrm{CO}_{2}$ emissions in the EU. While new buildings generally need less than three to five litres of heating oil per square meter per year, older buildings consume about 25 litres on average; some buildings even require up to 60 litres. Currently, about $35 \%$ of EU buildings are over 50 years old. By improving the energy efficiency of buildings, total EU energy consumption could be reduced by $5 \%$ to $6 \%$, whereas $\mathrm{CO}_{2}$ emissions might be lowered by about $5 \%[5]-[7]$.

In order to further stimulate an increased number of energy efficient buildings, the Energy Performance of Buildings Directive [8] states that after 31 December 2020, all new buildings will be Nearly Zero Energy Buildings (nZEBs), namely buildings with very high energy performance where the nearly zero or very low amount of energy required should be extensively covered by renewable sources produced onsite or nearby [9][10].

Therefore, the improvement of the energy performance of buildings is actually considered a crucial target which regards both new and old constructions and can be essentially reached by means of a proper design and upgrading of the edifice perimeter structures.

On the other hand, considering the influence that the façade features have on the indoor environmental conditions, properly designed configurations may positively affect the radiant field enveloping the human body in indoor environments [11], so that thermal comfort requisites are easily met.

In this context, materials can play a pivotal role in order to enhance the thermal behavior of the building envelope, adapting it to the climate condition of the building site; as a consequence this field has been characterized by developing innovations especially regarding the insulation structures (Vacuum Insulation Panels, Gas-Filled Panels, Aerogels, Phase Change Materials, etc.).

However, despite their reliable insulation features, rarely are these materials able to satisfy all the needed requirements; as a matter of fact, they often manifest vulnerability to time 
and weather conditions (sun beam, humidity, etc.), they may undergo reductions of their insulation properties after modest perforations and, besides, their structure rarely allows cutting for adaption at building site. Furthermore, at the current state of art, these innovative structures are rather expensive and this is the main cause which prevents their diffusion on a larger scale, whereas their global environmental impact (including energy and material use in production, emission of polluting agents and recycling issues) cannot be considered low or negligible.

From this last point of view, the ecological properties of the building materials have currently become essential for a complete assessment of the constructions. The demand for green building materials is rising sharply, especially for insulating materials from renewable resources.

Therefore, recent studies on this topic regard raw material resources originating from agricultural sources [12][13] or from waste or recycling [14], discussing their potential and costs [15][16], addressing the problem of thermal property change with humidity [17], assessing their structural properties [18] or discussing their LCA [19].

With a view to addressing all these issues, this paper has been aimed at identifying other types of structures made up of natural materials which, albeit characterized by poorer insulation properties, are less expensive, more versatile for adaption at building site and more environment-friendly, being composed of vegetal/ecological waste items and suitable for recycling matters.

As a contribution to this topic, this study aims to assess the insulation features of various structures made up of totally natural and biocompatible materials, in order to try to single out the optimal configurations. The studied mixtures, in fact, consist of a natural binder and a biocompatible inert material with various mass ratio compositions.

Particularly, the paper presents the preliminary results of some measurements regarding the thermal conductivity of three samples constructed respectively using dry platanus acerifolia fruits, cork plugs and cardboard as inert materials which were all grinded and blended in a paste of hydraulic lime (NHL 3.5) and water.

The results demonstrate that the thermal conductivities of the studied structures are adequate to insulation purposes, even though further improvement are also possible.

\section{MATERIALS AND METHODS}

\subsection{Measurement principles and used instrument}

The general measurement principle is based on the onedimensional Fourier law [20]:

$$
q=-k \frac{d t}{d x}
$$

where $q$ is heat flux $\left(\mathrm{W} / \mathrm{m}^{2}\right)$ flowing through the sample, $k$ its thermal conductivity $\left(\mathrm{W} \mathrm{m}^{-1} \mathrm{~K}^{-1}\right)$ and $d t / d x$ the temperature gradient $\left(\mathrm{K} \mathrm{m}^{-1}\right)$ on the isotherm flat surface of the sample.

If a flat sample is placed between two flat isothermal plates maintained at two different temperatures, and a uniform onedimensional temperature field has been stabilized, the heat flux in the sample should be orthogonal to the sample flat faces.

As a consequence, the temperature gradient can be determined by measurements of the difference between temperatures of the hot and cold plates $\left(\Delta t=t_{\text {hot }}-t_{\text {cold }}\right)$ and thickness of the sample $\Delta \mathrm{x}$, being in this case average temperature gradient $\mathrm{dt} / \mathrm{dx}$ equal to $\Delta \mathrm{t} / \Delta \mathrm{x}$.

The used instrument, exploiting these principles, is the FOX 314TM (Figure 1). It consists of the chamber and the base with keypad display section. All the electronics are housed in the base. Once the door of the chamber is opened, sample can be placed between two plates. The upper plate is stationary, whereas the lower one can move up and down by four independently controlled stepping motors. Four precise thickness readout digital sensors monitor the position of each corner of the lower plate. Each time a sample is inserted into the instrument and the stack is closed, the average thickness of the sample is determined within $+/-0.025 \mathrm{~mm}$ accuracy.

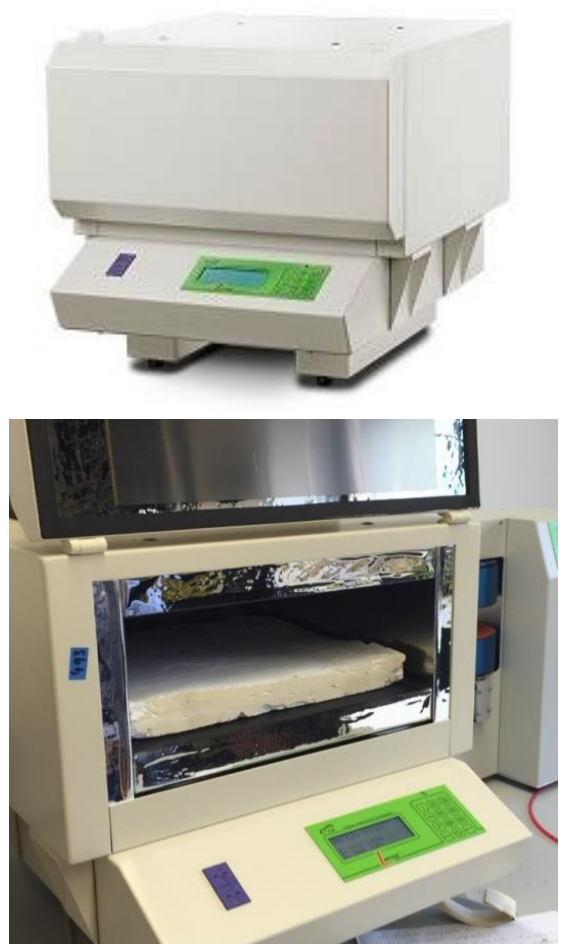

Figure 1. The used instrument: Fox $314^{\mathrm{TM}}$ heat flow meter

Heat Flow Meters (transducers) are bonded to the surfaces of both plates (Figure 2). Type E thermocouples are bonded in the center of each transducer. The thermocouples are positioned next to the surfaces of the plates and provide accurate readings of both sample surface temperatures.

As regards the functioning of the experimental apparatus, the two parallel plates are respectively heated and cooled by two arrays of solid-state Peltier elements which, for their lowmass and high-output, enable fast attainment of the temperature set-points. Plate temperature control is driven by the responsive thermocouples in close contact with the sample. An advanced temperature control algorithm continuously maintains the plate temperatures and rapidly brings the system to full thermal equilibrium.

Water-cooled metal heat sinks are bonded to the back sides of the Peltier elements. The waste heat is removed by a recirculating chiller system (Figure 3) which allows the Peltier elements to operate at the necessary power output.

Finally, in order to prevent edge heat losses, due to the finite dimensions of the sample, the meter apparatus is equipped with a linear gradient guard, an active guard area. 
Before starting measurements on a sample with unknown thermal conductivity, the heat flow meter must be calibrated using a standard sample having reliable known values of thermal conductivity $\mathrm{k}_{\mathrm{cal}}(\mathrm{t})$.

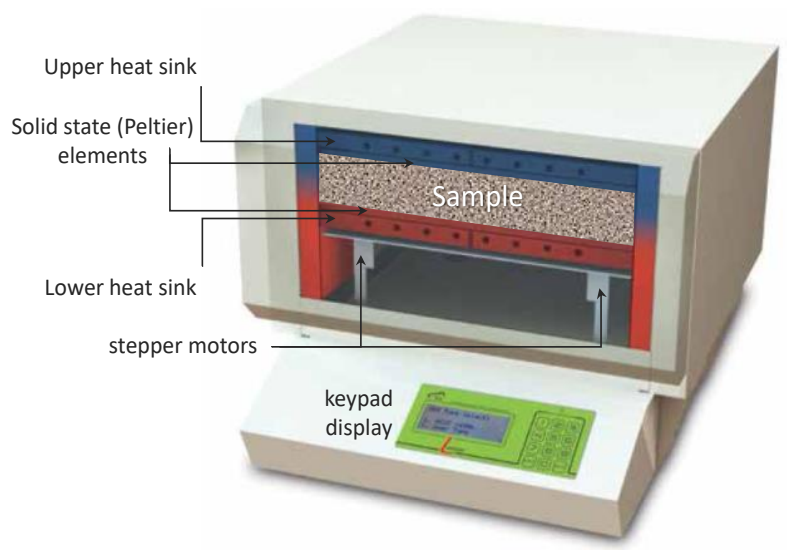

Figure 2. Structure of the Fox $314^{\mathrm{TM}}$ heat flow meter

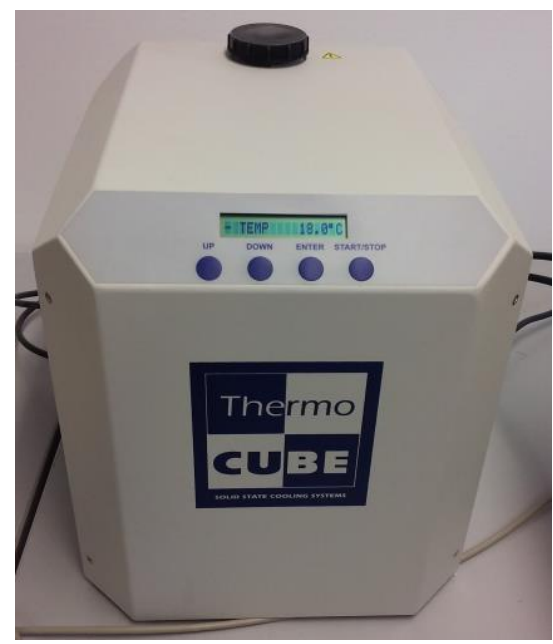

Figure 3. Recirculating chiller system

Electric signal from the transducer $\mathrm{Q}(\mu \mathrm{V})$ is proportional to the heat flux $\mathrm{q}\left(\mathrm{W} / \mathrm{m}^{2}\right)$ :

$q=Q \times S_{c a l}(t)$

where $S_{\text {cal }}(t)$ is the calibration factor $\left(\mathrm{W} \mathrm{m}^{-2} \mu \mathrm{V}^{-1}\right)$.

As the physical properties of the transducer change with temperature, the temperature calibration of the instrument using standard material is always necessary to get the temperature dependent calibration factor, $S_{c a l}(\mathrm{t})$, which is an instrument characteristic.

It is assessed by means of the equations:

$q=k_{c a l}\left(t_{c a l}\right) \frac{\Delta t_{c a l}}{\Delta x_{c a l}}=Q \times S_{c a l}\left(t_{c a l}\right)$

$S_{c a l}\left(t_{c a l}\right)=k_{c a l}\left(t_{c a l}\right) \frac{\Delta t_{c a l}}{\Delta x_{c a l}} \times \frac{1}{Q}$

During the calibration run, each of the two transducers has its own temperature, so that the calibration factors should be referred to their actual temperatures. Therefore, two separate sets of the calibration factors (namely $S_{c a l}^{u p}\left(t_{c a l}\right)$ for the upper plate and $S_{\text {cal }}^{\text {low }}\left(t_{c a l}\right)$ for the lower plate) are measured during the calibration run.

They are used for thermal conductivity calculation during the real measurement by means of the equation:

$k_{\text {test }}=S_{\text {cal }}(t) \times Q \times \frac{\Delta x}{\Delta t}$

which allows the calculation of the two values $k_{\text {test }}^{u p}\left(t_{\text {up }}\right)$ and $k_{\text {test }}^{\text {low }}\left(t_{\text {down }}\right)$ in correspondence of $S_{\text {cal }}^{\text {up }}\left(t_{\text {up }}\right)$ and $S_{\text {cal }}^{\text {low }}\left(t_{\text {low }}\right)$ respectively, where tup and tow are the correspondent temperature set for the upper and lower plate.

Average of two thermal conductivity values is a final result of thermal conductivity test.

\subsection{Preparation of the studied specimens}

Samples were realized by means of proper formworks (Figure 4) used to structure each item with the form and dimension complying with the requirement of the measurement chamber of the instrument.

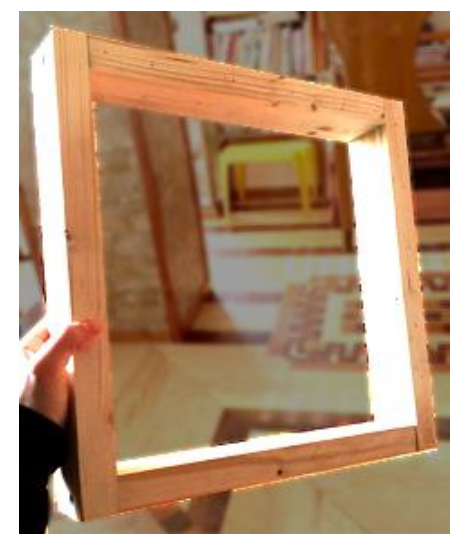

Figure 4. Structure of the used formwork

More precisely the specimens dimensions are: $30 \mathrm{~cm} \times 30$ $\mathrm{cm}$ with variable thickness, which was measured by the instrument every measurement run.

Three samples were constructed (Figure 5) using three different natural materials as inert matrix: platanus acerifolia fruits (Figure 6), cork plugs and cardboard.

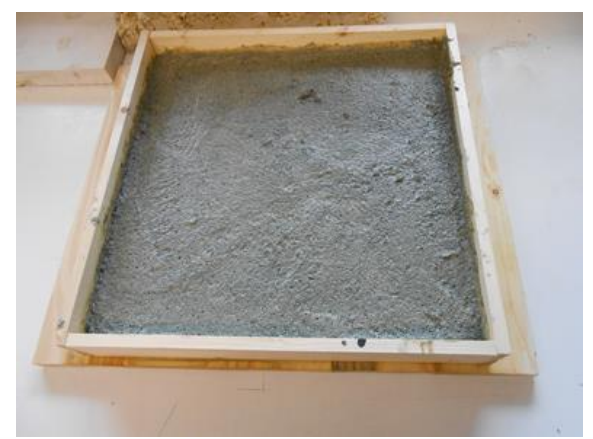

Figure 5. Typical structure of the samples 


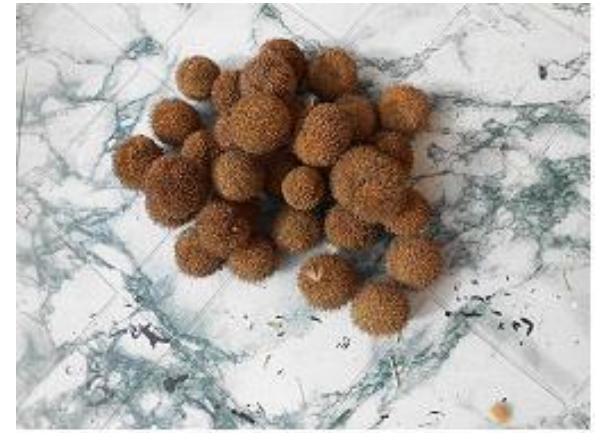

Figure 6. Desiccated platanus acerifolia fruits

The platanus acerifolia fruits were naturally desiccated and manually mashed (Figure 7), the cork plugs were all triturated (Figure 8) to form particles having a diameter smaller than $2 \mathrm{~mm}$, while the cardboard was cut into pieces and soaked into water.

The used binder is hydraulic lime NHL 3.5, selected for being a natural material (it is produced by heating -calcininglimestone that naturally contains clay and other impurities), for its quite fast set and for its high compressive strength.

The weight composition of the mixture constituting each sample is reported in Table 1, whereas in Figure 9 the weight shares are depicted.

With regards to this aspect, it must be highlighted that in the aim to construct sample $\mathrm{C}$, the cardboard was preliminary dampened, in order to allow it to be blended with the mixture. The water content of the mixture reported in Figure 9 is only referred to the quantity needed to blend the hydraulic lime and does not take into account the water used to damp the cardboard. On the contrary, the weight of the inert is referred to the wet cardboard and, therefore, it comprises the weight of the water used to damp the material.

Every mixture has been used to structure the correspondent sample, exploiting the formerly described formworks. The obtained dimensions, which do not usually employ the global amount of mixture, are reported in Table 2.

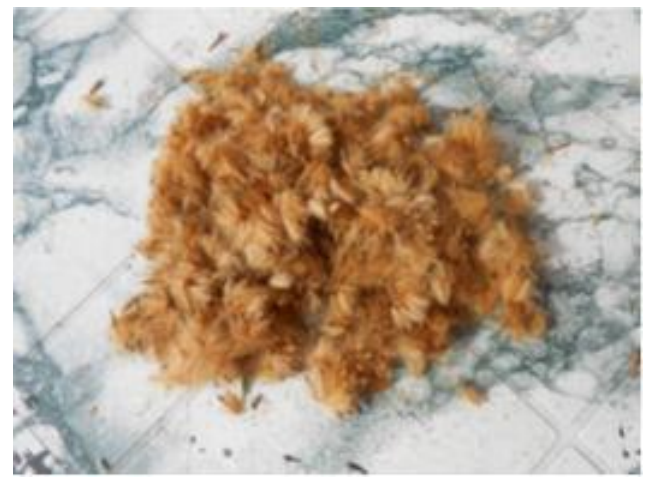

Figure 7. Crumbled desiccated platanus acerifolia fruits

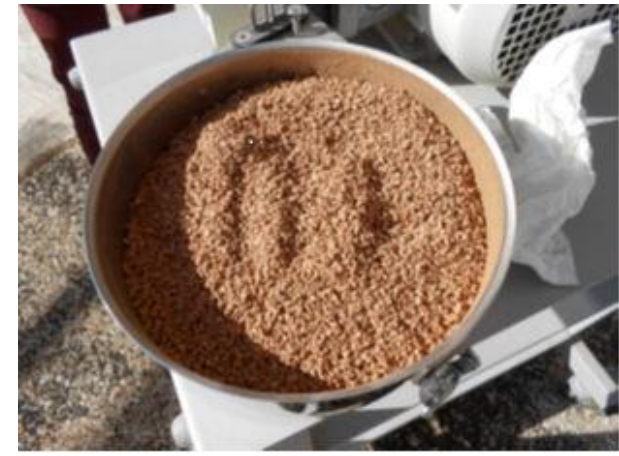

Figure 8. Triturated cork plugs

Table 1. Weight composition of the samples

\begin{tabular}{|c|c|c|c|c|c|}
\hline \multirow[b]{2}{*}{ Sample } & \multirow{2}{*}{$\begin{array}{l}\text { Inert } \\
\text { material }\end{array}$} & \multicolumn{4}{|l|}{ Weight $(\mathrm{g})$} \\
\hline & & $\begin{array}{l}\text { hydraulic } \\
\text { lime }\end{array}$ & $\begin{array}{l}\text { inert } \\
\text { material }\end{array}$ & water & TOTAL \\
\hline A & $\begin{array}{l}\text { platanus } \\
\text { acerifolia } \\
\text { fruits }\end{array}$ & 2700 & 600 & 2140 & 5440 \\
\hline B & cork plug & 766 & 340 & 810 & 1916 \\
\hline $\mathrm{C}$ & $\begin{array}{l}\text { Wet } \\
\text { cardboard }\end{array}$ & 911 & 2734 & 2500 & 6145 \\
\hline
\end{tabular}

After the construction, the samples were made rest into the formworks for a few days in order not to alter the homogeneity of the mixture with movement and, hence, at the end of this period they were weighted for the first time.

Table 2. Structure of the samples

\begin{tabular}{lllll}
\hline Sample & $\begin{array}{l}\text { Inert } \\
\text { material }\end{array}$ & \multicolumn{2}{c}{ Dimensions $(\mathrm{cm})$} & \\
\cline { 2 - 5 } & \multicolumn{1}{c}{ length } & width & thickness \\
\hline A & $\begin{array}{l}\text { platanus } \\
\text { acerifolia } \\
\text { fruits }\end{array}$ & 30 & 30 & 4.6 \\
\hline B & cork plug & 30 & 30 & 2.9 \\
\hline C & cardboard & 30 & 30 & 4.4 \\
\hline
\end{tabular}

All the samples underwent a natural drying process during which they were progressively weighted; as a result, the weight loss is reported in Figure 10.

It is worth noting that the weight of sample $\mathrm{C}$ reached a steady state more slowly than the other two, even though the global weight loss at the end of the drying process was higher.

This phenomenon is due to the mixture composition of sample $\mathrm{C}$, which has a smaller content of binder, and to the behavior of the cardboard which absorbs a great deal of water at the beginning, but slowly releases it during the drying process.

However, the sample will be further investigated, to verify the evolution of dry process and the achievement of stability conditions.

In Figure 11 the density of the three samples, at the end of the drying process, is reported. As expected, sample $\mathrm{C}$ has the lowest density, owing to the higher weight loss. 
Sample A

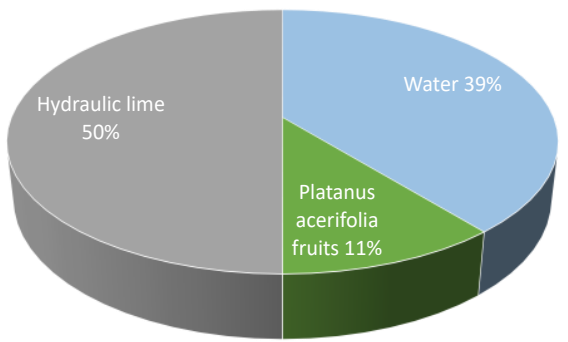

Sample B

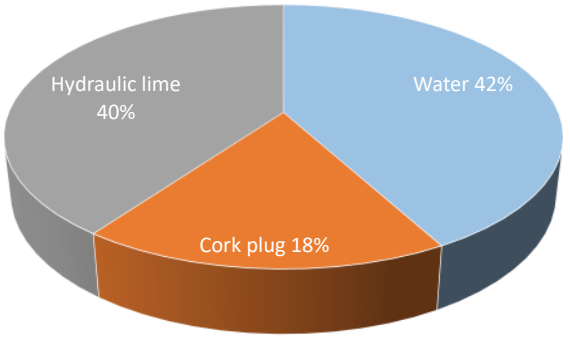

Sample C

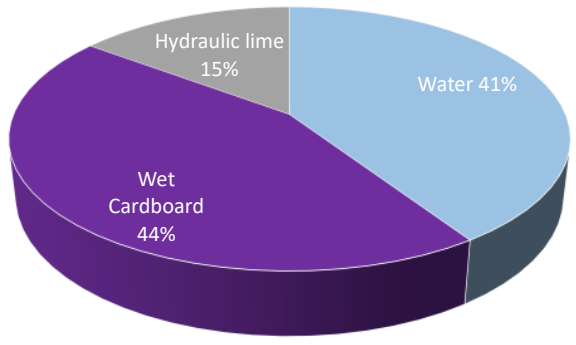

Figure 9. Weight shares of the studied samples
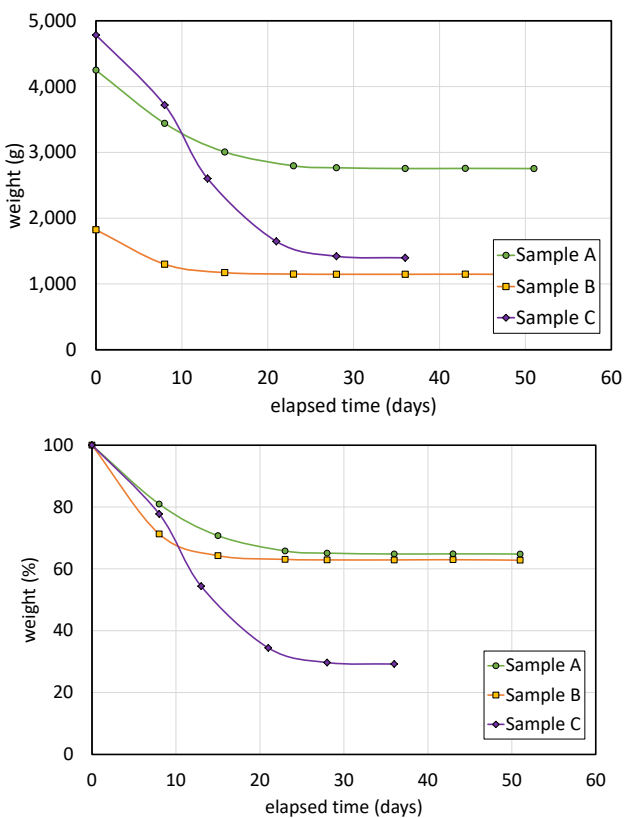

Figure 10. Weight loss of the studied samples

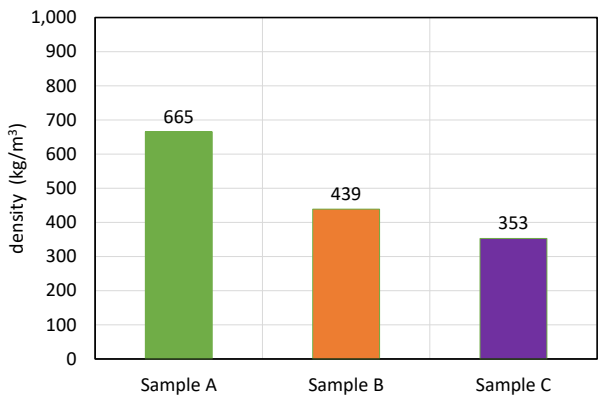

Figure 11. Density of the studied samples

\section{MEASUREMENT RESULTS}

The measurements involved several temperature gradients, in order to investigate the variation of the sample thermal conductivity with the temperature in the range between $0^{\circ} \mathrm{C}$ and $40^{\circ} \mathrm{C}$.

The ranges used were the ones reported in Table 3, where the lower limit, $\mathrm{t}_{\text {low }}$, namely the set-point value for the lower plate of the instrument, the higher limit, $t_{u p}$, that is the setpoint value fixed for the upper plate, and the average temperature, $t_{\text {avg }}$, are specified.

Table 3. Temperature ranges

\begin{tabular}{llll}
\hline Range ID & $t_{\text {low }}\left({ }^{\circ} \mathrm{C}\right)$ & $t_{\text {up }}\left({ }^{\circ} \mathrm{C}\right)$ & $t_{\text {avg }}\left({ }^{\circ} \mathrm{C}\right)$ \\
\hline 1 & 0 & 20 & 10 \\
\hline 2 & 5 & 25 & 15 \\
\hline 3 & 10 & 30 & 20 \\
\hline 4 & 15 & 35 & 25 \\
\hline 5 & 20 & 40 & 30 \\
\hline
\end{tabular}

The results of the thermal conductivity measurements are reported in Figure 12, which depicts their trend with temperature, and Table 4, which specifies the average values and the standard deviations.

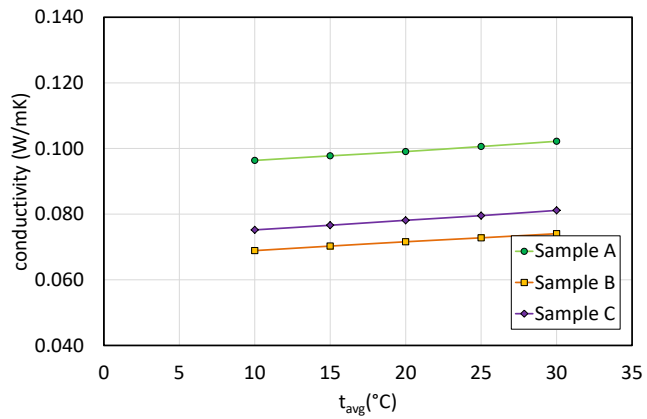

Figure 12. Measurement results

Table 4. Experimental results

\begin{tabular}{llll}
\hline Sample & Inert material & $\begin{array}{l}\mathrm{k} \\
\left(\mathrm{W} \mathrm{m}^{-1} \mathrm{~K}^{-1}\right)\end{array}$ & $\begin{array}{l}\text { Standard Deviation } \\
\left(\mathrm{W} \mathrm{m}^{-1} \mathrm{~K}^{-1}\right)\end{array}$ \\
\hline $\mathrm{A}$ & $\begin{array}{l}\text { platanus } \\
\text { acerifolia fruits }\end{array}$ & 0.0992 & 0.00205 \\
\hline $\mathrm{B}$ & cork plug & 0.0715 & 0.00182 \\
\hline $\mathrm{C}$ & cardboard & 0.0781 & 0.00209 \\
\hline
\end{tabular}


It can be noted that, in the studied ranges, the variation of the measured parameter with temperature is small.

Furthermore,

Figure 13 shows the variability of the thermal conductivity with the density of the material. Albeit the few available results do not allow a definitive statement on this topic, it could be highlighted that, as it is usually expected, the lowest density values allow the lowest thermal conductivity values to be reached.

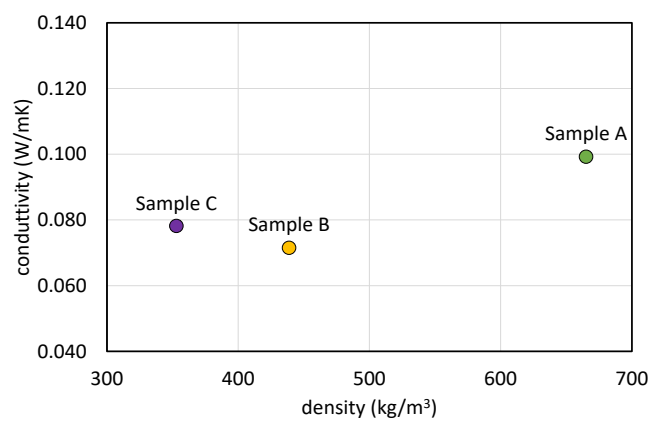

Figure 13. Thermal conductivity versus density

\section{CONCLUSIONS}

Nowadays, the demand for green building materials, especially insulating materials from renewable resources, is sharply rising. Natural material are emerging as low cost, lightweight and apparently environmentally superior alternatives to traditional matters in composites used in building constructions.

In this context, this paper reports the preliminary results of a research activity aimed at the assessment of the insulation features of various structures made up of totally natural and biocompatible materials, in order to try to single out the optimal configurations.

The studied mixtures, in fact, consist of a natural binder (such as hydraulic lime NHL 3.5) and a biocompatible inert material (such as platanus acerifolia fruits, natural cork and cardboard).

The results demonstrate that the thermal conductivities of the studied structures are lower than $0.1 \mathrm{~W} / \mathrm{mK}$, confirming that, albeit further improvement are possible by modifying the texture and composition of the compounds, these elements can be considered a good alternative to the most used insulating materials. Furthermore, being constructed using waste materials, they are a contribution to the recycling processes which can make the building industry more sustainable.

On the other hand, notwithstanding the encouraging results, additional analysis are needed for a complete assessment of the studied structures: mechanical resistance, impact of moisture content and the influence of the drying process on the thermal and mechanical properties should be furtherly investigated.

In this direction the prosecution of the research activity has been planned.

\section{REFERENCES}

[1] D. Gattuso, A. Greco, C. Marino, A. Nucara, M. Pietrafesa and F. Scopelliti, "Sustainable mobility: Environmental and economic analysis of a cable railway, powered by photovoltaic system," International Journal of Heat and Technology, vol. 34, pp. 7-14, 2016. DOI: 10.18280/ijht.340102.

[2] C. Marino, A. Nucara, M. Pietrafesa and A. Pudano, "The assessment of road traffic air pollution by means of an average emission parameter," Environmental Modeling and Assessment, vol. 21, pp. 53-69, 2016. DOI: 10.1007/s10666-015-9489-8.

[3] M. Kousoulidou, L. Ntziachristos, G. Mellios and Z. Samaras, "Road-transport emission projections to 2020 in European urban environments," Atmospheric Environment, vol. 42, pp. 7465-7475, 2008. DOI: 10.1016/j.atmosenv.2008.06.002.

[4] J. Lumbreras, M. Valdés, R. Borge and M. E. Rodríguez, "Assessment of vehicle emissions projections in Madrid (Spain) from 2004 to 2012 considering several control strategies," Transportation Research Part A: Policy and Practice, vol. 42, pp. 646-658, 2008. DOI: 10.1016/j.tra.2008.01.026.

EU, Energy Roadmap 2050, European Commission, 2011. [Online]. Available: http://ec.europa.eu/energy/en/topics/energystrategy/2050-energy-strategy.

[6] EU, A policy framework for climate and energy in the period from 2020 to 2030, European Commission, 2014. [Online]. Available: http://ec.europa.eu/energy/en/topics/energystrategy/2030-energy-strategy.

[7] EU, Energy 2020. A strategy for competitive, sustainable and secure energy, European Commission, 2010. [Online]. Available: https://ec.europa.eu/energy/en/topics/energystrategy/2020-energy-strategy.

[8] EU, Directive 2010/31/EU of the European Parliament and of the Council of 19 May 2010 on the energy performance of buildings, vol. Official Journal of the European Communities, L 153/13, 18 June 2010.

[9] A. Malara, C. Marino, A. Nucara, M. Pietrafesa, F. Scopelliti and G. Streva, "Energetic and economic analysis of shading effects on pv panels energy production," International Journal of Heat and Technology, 2016, vol. 34, pp. 465-472. DOI: 10.18280/ijht.340316.

[10] N. Aste, F. Leonforte and C. Del Pero, "Design, modeling and performance monitoring of a photovoltaic-thermal (PVT) water collector," Solar Energy, vol. 112, pp. 85-99, 2015. DOI: 10.1016/j.solener.2014. 11.025.

[11] C. Marino, A. Nucara and M. Pietrafesa, "Mapping of the indoor comfort conditions considering the effect of solar radiation," Solar Energy, vol. 113, pp. 63-77, 2015. DOI: 10.1016/j.solener.2014.12.020.

[12] A. Korjenic, V. Petránek, J. Zach and J. Hroudovà, "Development and performance evaluation of natural thermal-insulation materials composed of renewable resources," Energy and Buildings, vol. 43, pp. 25182523, 2011. DOI: 10.1016/j.enbuild.2011.06.012.

[13] A. Paiva, S. Pereira, A. Sá, D. Cruz, H. Varum and J. Pinto, "A contribution to the thermal insulation performance characterization of corn cob particleboards," Energy and Buildings, vol. 45, pp. 274-279, 2012. DOI: 10.1016/j.enbuild.2011.11.019.

[14] A. Patnaik, M. Mvubu, S. Muniyasamy, A. Botha and R. D. Anandjiwala, "Thermal and sound insulation 
materials from waste wool and recycled polyester fibers and their biodegradation studies," Energy and Buildings, vol. 92, pp. 161-169, 2015. DOI: 10.1016/j.enbuild.2015.01.056.

[15] H. R. Kymalainen and A. M. Sjoberg, "Flax and hemp fibres as raw materials for thermal insulations," Building and Environment, vol. 43, pp. 1261-1269, 2008. DOI: 10.1016/j.buildenv.2007.03.006.

[16] K. W. Corscadden, J. N. Biggs and D. K. Stiles, "Sheep's wool insulation: A sustainable alternative use for a renewable resource?," Resources, Conservation and Recycling, vol. 86, pp. 9-15, 2014. DOI: 10.1016/j.resconrec.2014.01.004.

[17] J. Zach, J. Hroudovà, J. Brozovsky, Z. Krejza and A. Gailius, "Development of thermal insulating materials on natural base for thermal insulation systems," Procedia Engineering, vol. 57, pp. 1288-1294, 2013. DOI: $10.1016 /$ j.proeng.2013.04.162.

[18] S. Benfratello, C. Capitano, G. Peri, G. Rizzo, G. Scaccianoce and G. Sorrentino, "Thermal and structural properties of a hemp-lime biocomposite," Construction and Building Materials, vol. 48, pp. 745-754, 2013. DOI: 10.1016/j.conbuildmat.2013.07. 096.

[19] S. V. Joshi, L. T. Drzal, A. K. Mohanty and S. Arora, "Are natural fiber composites environmentally superior to glass fiber reinforced composites?"

Composites Part A: Applied Science and Manufacturing, vol. 35, pp. 371-376, 2004. DOI: 10.1016/j.compositesa.2003.09.016.

[20] F. Kreith, R. M. Manglik and M. S. Bohn, Principles of Heat Transfer, vol. Cengage Learning, 2011.

\section{NOMENCLATURE}

$k$

$q$

Q

$S$

$t$

Apex

up

low

\section{Subscript}

cal

test thermal conductivity, $\mathrm{W} \mathrm{m}^{-1} \mathrm{~K}^{-1}$ heat flux, W/m

electric signal from the transducer, $\mu \mathrm{V}$ calibration factor, $\mathrm{W} \mathrm{m} \mathrm{m}^{-2} \mu \mathrm{V}^{-1}$ temperature, ${ }^{\circ} \mathrm{C}$

referred to the upper plate of the instrument referred to the lowest plate of the instrument

referred to the calibration run

referred to the actual measurement run 